\title{
Improvement of Cyclic Vomiting Syndrome with Outpatient Ketamine Infusions
}

\author{
Anna Carpenter ${ }^{\mathrm{a}} \quad$ David J. Levinthal ${ }^{\mathrm{b}} \quad$ David G. Binion $^{\mathrm{b}} \quad$ Trent Emerick $^{\mathrm{c}}$ \\ aDepartment of Anesthesiology, West Virginia University Ruby Memorial Hospital, \\ Morgantown, WV, USA; 'bivision of Gastroenterology, Hepatology, and Nutrition, \\ Department of Internal Medicine, University of Pittsburgh Medical Center, \\ Pittsburgh, PA, USA; 'Department of Anesthesiology and Perioperative Medicine, \\ University of Pittsburgh Medical Center, Pittsburgh, PA, USA
}

\section{Keywords}

Cyclic vomiting syndrome - Chronic abdominal pain · Ketamine $\cdot$ NMDA antagonist · Prophylactic therapy · Case report

\begin{abstract}
Cyclic vomiting syndrome (CVS) is a disorder characterized by recurrent flares of nausea and vomiting, often with significant abdominal pain, of several days duration. Although traditional prophylactic and abortive treatments for CVS are often successful, a subset of CVS patients with chronic abdominal pain may not respond as well to standard therapies. This report is the first, to our knowledge, to describe the use of outpatient ketamine infusions as therapy for refractory CVS. We describe a 63-year-old woman with history of CVS who presented with abdominal pain and recurrent episodes of nausea and vomiting. She first received ketamine during an inpatient admission for a CVS flare, with the aim of treating the abdominal pain. Given her improvement, she was offered a series of outpatient ketamine infusions, which led to a significant reduction in her symptoms. Thus, ketamine may be useful as both an abortive and prophylactic therapy in CVS. Prior reports have noted the anti-emetic effects of ketamine in the perioperative setting, and there is emerging evidence for the use of ketamine infusions
\end{abstract}

Trent Emerick
Department of Anesthesiology and Perioperative Medicine
University of Pittsburgh Medical Center
36015th Avenue, Floor 6, Pittsburgh, PA 15213 (USA)
emericktd@upmc.edu




\section{Case Reports in Gastroenterology}

\begin{tabular}{l|l}
\hline Case Rep Gastroenterol 2021;15:9-16 \\
\hline DOI: 10.1159/000510933 & $\begin{array}{l}\text { ○ 2021 The Author(s). Published by S. Karger AG, Basel } \\
\text { www.karger.com/crg }\end{array}$ \\
\hline
\end{tabular}

Carpenter et al.: Improvement of Cyclic Vomiting Syndrome with Outpatient Ketamine Infusions

for the treatment of chronic pain. However, this report is the first to describe ketamine as a potential prophylactic treatment for CVS.

(c) 2021 The Author(s)

Published by S. Karger AG, Basel

\section{Introduction}

Cyclic vomiting syndrome (CVS) is a disorder characterized by episodes of nausea and vomiting, often with intense abdominal pain, which generally last from 1 to 5 days before transitioning to the inter-episodic phase that is typically free of symptoms and may last weeks to several months or more $[1,2]$. The cause of CVS remains unclear. Most patients with CVS respond to treatments that include supportive measures, medications (both prophylactic and abortive therapy), and the avoidance of suspected CVS triggers [1,2]. The medications most effective for CVS prophylaxis include tricyclic antidepressants, antiepileptic medications, and neurokinin-1 receptor antagonists [2]. Abortive therapies for CVS include triptans, as well as anti-emetic and sedative medications that include serotonin receptor antagonists, phenothiazines, antihistamines, cannabinoids, neurokinin-1 receptor antagonists and benzodiazepines [2]. Yet, CVS patients with chronic abdominal pain that outlast their initial CVS flare may represent a subgroup that is particularly refractory to these standard measures.

Ketamine is a noncompetitive antagonist of the N-methyl-d-aspartate (NMDA) receptor used primarily as a dissociative anesthetic [3]. There has been a resurgence of interest in using ketamine to treat acute and chronic pain as well as severe forms of mood disorders such as post-traumatic stress disorder, anxiety, and depression [4, 5]. The potential effects of ketamine on gastrointestinal symptoms have not been a major focus of study. Some studies have shown a decrease in nausea and vomiting in patients receiving ketamine perioperatively [68]. It is unclear if this reflects a direct effect of the medication, or if the improvement in nausea and vomiting is a secondary effect due to sparing the need for opiates.

There is a paucity of data on ketamine use in those with CVS. Ahuja et al. [9] first described a case series of 20 adult patients receiving ketamine boluses in the emergency department as abortive therapy for CVS attacks. This report demonstrated that more than half of these patients had a clinical response, and that this effect was dose dependent. A prospective trial using ketamine infusion combined with chlorpromazine showed benefits for patients presenting to the ED with intractable nausea and vomiting [10]. However, our search of the literature did not reveal any prior reports of outpatient ketamine infusions for CVS prophylactic treatment in those with or without chronic abdominal pain.

\section{Case Presentation}

\section{Patient Information}

This patient is a 63-year-old female (BMI 21.6) with a past medical history of migraines, postural orthostatic tachycardia, anxiety, chronic abdominal pain, and CVS. The patient had experienced chronic diarrhea since she was a teenager, and had suffered from recurrent Clostridium difficile colitis infections several years prior to presentation. Her symptoms of chronic, 


\section{Case Reports in Gastroenterology}

Case Rep Gastroenterol 2021;15:9-16

DOI: $10.1159 / 000510933$

(c) 2021 The Author(s). Published by S. Karger AG, Basel www.karger.com/crg

Carpenter et al.: Improvement of Cyclic Vomiting Syndrome with Outpatient Ketamine Infusions

diffuse abdominal pain and daily diarrhea (6-8 bowel movements/day) had become progressively worse over the few years prior to presentation. She also complained of frequent nausea (typically without vomiting unless in the midst of a CVS flare), poor appetite, and post-prandial abdominal bloating and discomfort. All of these symptoms had worsened more acutely in the 6 months preceding this visit.

The symptoms of abdominal pain, nausea and vomiting necessitated frequent admissions for inpatient management. She followed closely with her gastroenterologist for fluid and electrolyte replacement and monitoring, and she received IV fluids boluses at home via a central line. She was no longer able to continue her work as a registered nurse given the severity of her symptoms. She was hesitant to leave her home or engage in social activities because she feared she would have a CVS exacerbation in a public setting.

Her history of anxiety was longstanding, and responded to alprazolam $0.5 \mathrm{mg}$ TID as the primary anxiety treatment for years. She had never been formally evaluated by a psychiatrist nor been involved in long-term psychological therapy, but had been briefly evaluated by behavioral health specialists. In the recent years, her anxiety had worsened secondary to her CVS and the chronic abdominal pain.

She had trialed numerous other therapies for her CVS and chronic abdominal pain. She also failed dietary modifications including avoiding specific vegetables, dairy-free diet, and a gluten-free diet. Prior outpatient therapies included atropine/diphenoxylate, ondansetron, granisetron, hydroxyzine, levocarnitine, nortriptyline, amitriptyline, topiramate, aprepitant, promethazine, prochlorphenazine, alprazolam, lipase/protease/amylase, probiotics, dranabinol, tincture of opium, hydrocodone/acetaminophen, and home intravenous fluid replacement therapy. The pain also caused difficulty in sleeping, which was refractory to therapy including amitriptyline, topiramate, zolpidem and eszopiclone. An abbreviated timeline of the patient's medical history is presented in Table 1.

Her family history included ulcerative colitis in her mother, and irritable bowel syndrome in multiple other family members. In addition to the surgeries listed in Table 1, the patient also had a right shoulder arthroscopy in 1998, a vocal cord polyp removed in 2008, and a left shoulder arthroscopy in 2017.

\section{Diagnostic Assessment}

The patient had an extensive diagnostic workup for causes of her abdominal symptoms and cyclic vomiting. This included multiple prior endoscopies and colonoscopies, which showed mild chronic gastritis, diverticulosis, and scattered erosions at the terminal ileum (biopsy negative for inflammatory bowel disease). Cross-sectional imaging demonstrated a potential jejunal stricture with no clear correlate during an exploratory laparotomy.

\section{Interventions}

The patient had previously experienced multiple CVS flares, many of which required hospitalization, during which she had typically received parenteral opiates and benzodiazepines. In the 2 years prior to receiving outpatient ketamine infusions, the patient had been in the emergency department 22 times and admitted 13 times. Interestingly, the patient had received and tolerated bolus doses of ketamine during prior endoscopies over this span of time.

\section{Karger'=}




\section{Case Reports in Gastroenterology}

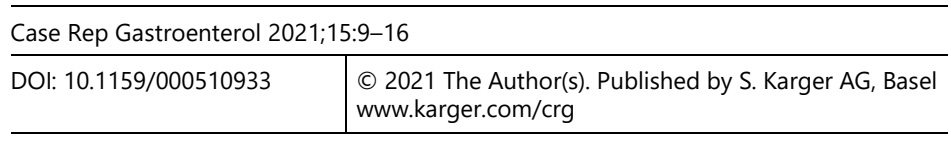

Carpenter et al.: Improvement of Cyclic Vomiting Syndrome with Outpatient Ketamine Infusions

Thus, ketamine was trialed during some of the ED visits in an attempt to abort the CVS flare. These ketamine infusions were successful in reducing abdominal pain, nausea and vomiting, and in some cases effectively aborted a CVS attack and allowing a discharge to home. Furthermore, during a few of the inpatient hospitalizations for her cyclical vomiting syndrome prior to 2018 , she received ketamine IV infusions (5 mg per hour for 24-48 h) which consistently and significantly reduced her symptoms during the hospitalization. Thus, there was a substantial signal that this patient could respond to ketamine with therapeutic benefits to reduce acute abdominal pain, nausea, and vomiting.

The objective of performing outpatient ketamine infusions was to assess whether this approach could prevent and minimize future hospital admissions due to chronic abdominal pain and CVS attacks. The initial visit to discuss outpatient ketamine infusions occurred in the chronic pain clinic in August 2018. The first outpatient ketamine infusion took place in October 2018, which was administered IV at $25 \mathrm{mg}$ per hour for $4 \mathrm{~h}$ (total dose $100 \mathrm{mg}$ ), followed by $2 \mathrm{~h}$ of monitoring, prior to discharge from the infusion center.

The patient received additional ketamine infusions (same rate and total dose) in February 2019, July 2019, and November 2019. She also received an additional ketamine infusion in February 2020 at a slightly higher dose of $30 \mathrm{mg}$ per hour for $4 \mathrm{~h}$ (per an updated outpatient ketamine infusion protocol). The schedule of ketamine infusions was patient-driven, triggered by any perceived worsening of nausea, vomiting, or abdominal pain. Her monthly controlled substance use has remained largely unchanged since starting the ketamine infusions. At the current time, she remains on alprazolam $0.5 \mathrm{mg}$ TID (\#90), dronabinol $10 \mathrm{mg}$ BID (\#60), and hydrocodone/acetaminophen 7.5/325 mg five times daily (\#150). She also has alprazolam 2 mg ODT (\#20) available for use as CVS abortive therapy.

\section{Follow-Up and Outcomes}

The patient experienced improved daily abdominal pain and complete resolution of her CVS over the 5 months following the first outpatient infusion in October 2018. In the 12 months prior to the first outpatient ketamine infusion, the patient had a total of seven hospital admissions and 10 separate emergency room visits for CVS attacks. After the series of outpatient ketamine infusions were initiated, the patient experienced one CVS flare that led to an ED visit and no CVS-related admissions for nearly 6 months (although unrelated, the patient presented to the ED for an exacerbation of shingles in mid-December 2018). The patient did experience a cluster of four ED visits and three admissions for CVS flares over a several week span in late April to mid-May 2019. However, there have been no further CVS flares since May 2019 (as of July 2020). Thus, with about 20 months of follow-up since the first ketamine infusion, there has been an obvious and substantial reduction in CVS attacks and overall improvement in chronic abdominal pain. The patient has not reported any side effects from the infusions.

\section{Karger'=}




\section{Case Reports in Gastroenterology}

\begin{tabular}{l|l}
\hline Case Rep Gastroenterol 2021;15:9-16 \\
\hline DOI: 10.1159/000510933 & $\begin{array}{l}\text { ○ 2021 The Author(s). Published by S. Karger AG, Basel } \\
\text { www.karger.com/crg }\end{array}$ \\
\hline
\end{tabular}

Carpenter et al.: Improvement of Cyclic Vomiting Syndrome with Outpatient Ketamine Infusions

\section{Discussion}

Many patients with CVS experience daily symptoms, including chronic abdominal pain, between CVS attacks, and these clinical features may predict a disease course refractory to standard therapies. Any improvement in the treatment of CVS patients with this phenotype could be important, as this group not only suffers substantial reductions in quality of life and high rates of disability, but presents a heavy burden on the healthcare system due to recurrent ED and inpatient admissions [11].

In this case report, the exposure to ketamine was acutely helpful for reducing abdominal pain, nausea and vomiting and in some instances in aborting a CVS flare. Overall, outpatient ketamine infusions were associated with improved abdominal pain and a substantial reduction in the frequency of CVS attacks that translated into an overall reduction in ED and inpatient hospitalizations. The patient is very satisfied with the results compared to other treatment modalities in the past. Yet, the patient has still utilized the ED and been admitted to the hospital since the first outpatient ketamine infusion. One limitation of our report is that reduction in frequency of ED visits and hospital admissions may represent a natural variation in her disease course, rather than being solely attributable to the impact of ketamine infusions. However, this seems less likely, as the overall numbers of ED visits and inpatient hospitalizations is dramatically lower than the baseline rates established over the prior 2 years prior to ketamine infusion. In fact, the vast majority of the 20 months period since the initiation of ketamine infusion has been largely free of CVS exacerbations.

The mechanism of action by which ketamine has improved this patient's abdominal pain and CVS control is unclear. Possible mechanisms by which this medication may have acted include direct analgesia, treatment of her underlying mood disorder, and/or direct reduction of neural excitability in the neural circuits critical for recurrent nausea and vomiting [12]. Ketamine is a noncompetitive antagonist at the phencyclidine binding site of the N-methyl-d-aspartate (NMDA) receptor [3]. These receptors widely expressed in the central nervous system, and inhibition of NMDA receptors primarily reduces excitatory neural transmission with longlasting neuromodulatory effects [3]. Ketamine may also partially activate opioid receptors (mu > kappa > sigma), inhibit nicotinic and muscarinic cholinergic receptors, lead to blockade of sodium and potassium channels, and activate dopamine receptors and L-type voltage-gated calcium channels [4]. Despite these disparate impacts on multiple receptor systems, ketamine use is not frequently associated with major side effects. However, side effects of ketamine include potential development of hepatotoxicity and cystitis $[13,14]$, which appear to be more common in very high doses and with illicitly-sourced ketamine, rather than with the doses we describe here.

We observed lasting improvements in the patient's chronic abdominal pain and CVS attack frequency following ketamine infusion. The analgesic effects of ketamine function primarily over acute periods, but emerging evidence suggests that ketamine exposure can have longer lasting impact on pain, potentially by enhancing the activity of the descending inhibitory pain pathway [5]. This patient had sustained relief lasting at least 3 months from a single $100 \mathrm{mg}$ ketamine infusion, which is notable, and makes acute analgesic effects less likely to be the prime mechanism. There is no clear information about the lasting improvements in nausea 


\section{Case Reports in Gastroenterology}

Case Rep Gastroenterol 2021;15:9-16

DOI: 10.1159/000510933

(c) 2021 The Author(s). Published by S. Karger AG, Basel www.karger.com/crg

Carpenter et al:: Improvement of Cyclic Vomiting Syndrome with Outpatient Ketamine Infusions

and vomiting following ketamine exposure. Studies of ketamine used in the perioperative setting have shown a reduction in nausea and vomiting [6,7]. Even in this setting, it is unclear if this reflects a direct effect of the medication itself or a secondary benefit driven by spared use of other anesthetics that may cause nausea and vomiting.

This patient does not have a diagnosis of depression or post-traumatic stress disorder, but she does suffer from significant anxiety. There are significant overlaps in the neurobiology of mood disorders, and emerging evidence suggests efficacy of ketamine in the treatment of a wide range of affective disorders and post-traumatic stress disorder. The anti-depressive effects of ketamine appear to begin approximately $4 \mathrm{~h}$ after infusion and last for approximately 2 weeks or more [4]. One cannot rule out a secondary improvement in this patient's chronic pain and CVS flare frequency simply due to ketamine-induced improvements in mood and anxiety. However, given chronic and continued treatment with benzodiazepines, it seems unlikely that this patient has experienced an improvement in abdominal pain and CVS control based solely on marginal improvements in anxiety.

Thus, the specific mechanisms by which ketamine infusions led to improvements in chronic abdominal pain and CVS attack frequency are likely multifactorial. Ketamine has such disparate potential impacts on neural activity across different neural circuits, that exposure to the drug targeted several mechanisms in parallel. Yet, the significant improvement our patient experienced with the ketamine infusions was striking. Further investigations in other CVS patients should explore whether the therapeutic effects of ketamine infusion therapy is restricted to those with chronic abdominal pain or if this intervention could potentially help a broader range of adult CVS patients who are refractory to traditional therapies.

\section{Statement of Ethics}

The subject has given written informed consent to publish the case.

\section{Conflict of Interest Statement}

Anna Carpenter - no competing interests to disclose; David J. Levinthal - Advisory Board, Takeda Pharmaceuticals, Alnylam Pharmaceuticals, and InControl Medical; David G. Binion no competing interests to disclose; Trent Emerick - no competing interests to disclose.

\section{Funding Sources}

No specific funding was available to develop this case report.

\section{Karger'=}




\section{Case Reports in Gastroenterology}

\section{Author Contributions}

A.C. performed the initial chart review and drafted the initial form of the manuscript. D.J.L. helped with chart review and made major edits to the manuscript. D.G.B. helped with edits to the manuscript. T.E. helped with chart review and with writing the manuscript. All authors read and approved the final manuscript.

\section{References}

1 Hayes WJ, VanGilder D, Berendse J, Lemon MD, Kappes JA. Cyclic Vomiting Syndrome: Diagnostic Approach and Current Management Strategies. Clin Exp Gastroenterol. 2018;11:77-84.

2 Venkatesan T, Levinthal DJ, Tarbell SE, Jaradeh SS, Hasler WL, Issenman RM, et al. Guidelines on management of cyclic vomiting syndrome in adults by the American Neurogastroenterology and Motility Society and the Cyclic Vomiting Syndrome Association. Neurogastroenterol Motil. 2019;31(S2 Suppl 2):e13604.

3 Cohen SP, Liao W, Gupta A, Plunkett A. Ketamine in pain management. Adv Psychosom Med. 2011;30:13961.

4 Sanacora G, Frye MA, McDonald W, Mathew SJ, Turner MS, Schatzberg AF, et al. A Consensus Statement on the Use of Ketamine in the Treatment of Mood Disorders. JAMA Psychiatry. 2017;74(4):399-405.

5 Cohen SP, Bhatia A, Buvanendran A, Schwenk ES, Wasan AD, Hurley RW, et al. Consensus Guidelines on the Use of Intravenous Ketamine Infusions for Chronic Pain from the American Society of Regionals Anesthesia and Pain Medicine, the American Society of Anesthesiologists. Reg Anesth Pain Med. 2018;43:521-46.

6 Laskowski K, Stirling A, McKay WP, Lim HJ. A systematic review of intravenous ketamine for postoperative analgesia. Can J Anaesth. 2011;58(10):911-23.

7 Bell RF, Dahl JB, Moore RA, Kalso E. Peri-operative ketamine for acute post-operative pain: a quantitative and qualitative systematic review (Cochrane review). Acta Anaesthesiol Scand. 2005;49(10):1405-28.

8 Wang L, Johnston B, Kaushal A, Cheng D, Zhu F, Martin J. Ketamine added to morphine or hydromorphone patient-controlled analgesia for acute postoperative pain in adults: a systematic review and meta-analysis of randomized trials. Can J Anaesth. 2016;63(3):311-25.

9 Ahuja A, Kingsley M, Diable C, Binion D, Levinthal D. Ketamine as A Novel Abortive Therapy for Cyclic Vomiting Syndrome Attacks. Gastroenterology. 2018;154(6):S-558-9.

10 Valdovinos E, Frazee B, Hailozian C, Haro D, Herring AA. Nonopioid, Nonbenzodiazepine Treatment Approach For Intractable Nausea and Vomiting in the Emergency Department. J Clin Gastroenterol. 2020 Apr;54(4):327-32.

11 Lacy BE, Parkman HP, Camilleri M. Chronic Nausea and Vomiting: evaluation and Treatment. Am J Gastroenterol. 2018;113(5):647-59.

12 Levinthal DJ. The Cyclic Vomiting Syndrome Threshold: A Framework for Understanding Pathogenesis and Predicting Successful Treatments. Clin Transl Gastroenterol. 2016;7(10):e198.

13 Rajandram R, Yap NY, Ong TA, Mun KS, Wali HA, Hasan MS, et al. Oral ketamine induced pathological changes of the urinary tract in a rat model. Malays J Pathol. 2017;39:47-53.

14 Noppers IM, Niesters M, Aarts LP, Bauer MC, Drewes AM, Dahan A, et al. Drug-induced liver injury following a repeated course of ketamine treatment for chronic pain in CRPS type 1 patients: a report of 3 cases. Pain. 2011;152(9):2173-8. 


\section{Case Reports in Gastroenterology}

Case Rep Gastroenterol 2021;15:9-16

DOI: $10.1159 / 000510933$

(C)

(C) 2021 The Author(s). Published by S. Karger AG, Basel www.karger.com/crg

Carpenter et al.: Improvement of Cyclic Vomiting Syndrome with Outpatient Ketamine Infusions

Table 1. Chronological timeline

\begin{tabular}{|c|c|}
\hline Date & Event \\
\hline 1955 & Date of birth \\
\hline 1969-1975 & Onset of chronic diarrhea and chronic migraines began during teen years \\
\hline 2009 & $\begin{array}{l}\text { Abdominal sacral colpopexy, cystoscopy, total abdominal hysterectomy, Burch colposuspension, paravaginal defect } \\
\text { repair }\end{array}$ \\
\hline 2010 & Initial diagnosis of Crohn's disease \\
\hline 2011 & First visit at digestive disorder center (gastroenterology), celiac sprue diagnosis \\
\hline 2011 & $\begin{array}{l}\text { Endoscopies and colonoscopies without particularly notable findings (chronic mild gastritis and reflux esophagitis; } \\
\text { normal colon; scattered erosions in terminal ileum that were negative for Crohn's disease) }\end{array}$ \\
\hline 2012 & CVS diagnosis \\
\hline 2012 & $\begin{array}{l}\text { Exploratory laparotomy for LUQ pain/obstruction symptoms; full thickness biopsy of jejunum with no evidence of mu- } \\
\text { cosal or mural disease }\end{array}$ \\
\hline $2013-2014$ & $\begin{array}{l}\text { Recurrent Clostridium difficile infections (treated with oral vancomycin; eventual clearance of toxin with no recurrence } \\
\text { since) }\end{array}$ \\
\hline 2015 & Left chest port placed for IV fluid infusions due to chronic diarrhea \\
\hline 2017 & Ketamine given in ED for CVS symptoms \\
\hline 2017-2018 & Emergency department visits in the 12 months prior to outpatient ketamine infusions (10) \\
\hline 2017-2018 & Hospital admissions in the 12 months prior to outpatient ketamine infusions (7) \\
\hline August 2018 & First visit to chronic pain clinic \\
\hline October 2018 & First outpatient chronic pain ketamine infusion \\
\hline Feb 2019, July 2019 & Subsequent ketamine infusions \\
\hline $2018-2020$ & Emergency department visits in the 20 months after first outpatient ketamine infusion (4) \\
\hline $2018-2020$ & Hospital admissions in the 20 months after outpatient ketamine infusion (3) \\
\hline
\end{tabular}

